\title{
Violência contra professores: realidades da Educação Física no ensino médio de escolas de uma cidade mineira
}

\section{RESUMO}

O objetivo deste estudo é identificar e analisar concepções e percepções de violência sofridas por professores de Educação Física escolar (EF) e de outras áreas do conhecimento, da cidade de Viçosa, Minas Gerais, Brasil. A pesquisa é de natureza qualitativa. Utilizou-se como instrumento de coleta de dados uma entrevista semiestruturada. Empregou-se a técnica de análise de conteúdo. Três categorias foram identificadas, a saber: 1) Escola como espaço de reprodução de violências; 2) professores e o cotidiano de violências; 3) violências e desvalorização profissional. Há pontos comuns a todos os docentes, bem como específicos da violência percebida sofrida por professores de EF. Estas são relacionadas a: ao espaço de aula; intencionalidade pedagógica ou sua falta; e credibilidade do componente curricular e avaliação.

PALAVRAS-CHAVE: Professores; Educação física; Violência

\section{Carolina Quintas Maitan}

Licenciada em Educação Física Universidade Federal de Viçosa,

Departamento de Educação Física, Viçosa, Brasil carolina.maitan@ufv.br https://orcid.org/0000-0001-9698-4988

Doiara Silva dos Santos

Doutora em Educação Física Universidade Federal de Viçosa, Departamento de Educação Física, Viçosa, Brasil santosdoiara@ufv.br https://orcid.org/0000-0002-4718-7226 
Violence against teachers: Physical Education realities at high schools from a city in Minas Gerais

\begin{abstract}
This study aims to identify and analyze teachers' and Physical Education teachers' conceptions and perceptions of violence, in Viçosa, Minas Gerais, Brazil. This is a qualitative, descriptive and exploratory research, in which we conducted semi-structured interview as data collection instrument. The analysis was performed using content analysis. Three categories were identified: 1) school as a space that reproduces violence; 2) teachers and a daily violence context; and 3) violence and teachers' devaluation. Results point to common and specific factors related to perception of violence by teachers and Physical Education teachers, the latter linked to content specificity, spaces and evaluation in Physical Education classes. They are related to classes' spaces; pedagogical intentionality or its absence; and the course's credibility and evaluation.
\end{abstract}

KEYWORDS: Teachers; Physical education; Violence

Violencia contra los docentes: realidades de la Educación Física en las escuelas secundarias de una ciudad de Minas Gerais

\title{
RESUMEN
}

El objetivo de este estudio es identificar y analizar las concepciones y percepciones de la violencia que sufren los docentes de Educación Física (EF) y docentes de otras áreas del conocimiento en la ciudad de Viçosa, Minas Gerais, Brasil. La investigación es de naturaleza cualitativa. Se utilizó una entrevista semiestructurada como instrumento de recolección de datos. Se utilizó la técnica de análisis de contenido. Se identificaron tres categorías, a saber: 1) La escuela como espacio de reproducción de la violencia; 2) maestros y violencia cotidiana; 3) violencia y desvalorización profesional. Hay puntos comunes a todos los docentes, así como aspectos específicos de la percepción de violencia que sufren los docentes de EF. Estos están relacionados con: el espacio del aula; intencionalidad pedagógica o su falta; y credibilidad del componente curricular y de evaluación

PALABRAS-CLAVE: Profesores; Educación física; Violencia 


\section{INTRODUÇÃO}

Em todos os contextos históricos da humanidade a violência se manifestou na vida social, ancorada por certos modos de pensar e por comportamentos que se estabelecem nas relações entre os sujeitos sociais. A violência é um fato social e, como tal, um fenômeno complexo e dinâmico que, ao longo do tempo, é sujeitado a mecanismos de organização e regulação social, por meio de regras e processos civilizatórios, a partir de diferentes instituições sociais, tais como a família, o governo, a religião, a escola, o sistema jurídico, etc. (ELIAS; DUNNING, 1992).

$\mathrm{Na}$ literatura científica, diversos autores conceituam a violência, expressando-se a partir de diferentes concepções e perspectivas, incluindo-se a articulação entre as Ciências da Saúde e as Ciências Humanas e Sociais, que se complementam em perspectivas e tipologias. Schraiber, D' Oliveira e Couto (2006), por exemplo, afirmam que a violência é uma questão social e de saúde pública, apresentada como uma violação de direitos, que se expressa em diversos contextos, afetando diretamente direitos humanos e sociais.

A Organização Mundial da Saúde (OMS), por sua vez, definiu a violência como:

O uso intencional da força física ou do poder, real ou em ameaça, contra si próprio, contra outra pessoa, ou contra um grupo ou uma comunidade, que resulte ou tenha grande possibilidade de resultar em lesão (OMS, 2002, p. p.1165).

O conceito da OMS, tal como outros, adentra na tipologia das violências e abrange, como se nota, violências físicas, psicológicas, e sociais. De fato, desigualdades sociais culminam em aumento significativo dos índices de violência de diferentes formas (CARDIA; SCHIFFER, 2002). Este estudo se apoia na conceituação mais ampla que articula as Ciências da Saúde com as Ciências Humanas e Sociais, inclusive na abrangência das tipologias compreendidas nestas áreas.

No campo das Ciências Sociais, com frequência, destaca-se a tipologia da violência simbólica, apropriada a partir da teorização de Pierre de Bourdieu. De acordo com Tiradentes (2015), é fundamental discutir a violência simbólica, pois, ela pode ser verificada em diversos setores sociais, inclusive nas escolas. Esse tipo de violência, é caracterizada pela ausência de ameaça física, mas, que ocasiona danos morais e psicológicos. Nela, apoia-se a ideia de uma determinação de uma classe dominante, a qual manifesta a legitimidade de um poder social, econômico, institucional, simbólico ou cultural. Como exemplos dessa violência podemos citar os atos discriminatórios em razão de posição socioeconômica, gênero, questão étnico-racial, profissão, etc. 
A escola, decerto, não é uma instituição social isenta às expressões da violência (física, psicológica, simbólica, etc.). O binômio violência escolar tem sido objeto de investigação no campo acadêmico e pesquisas demonstram que as expressões da violência neste ambiente se dão de variadas maneiras, inclusive contra os professores (ABRAMOVAY, 2003; ABRAMOVAY, 2005).

Entretanto, Aragão Pinheiro et al. (2020) indicam que tanto na literatura acadêmica brasileira quanto internacional, a maior parte dos estudos sobre violência escolar tende a se concentrar nas violências sofridas pelos alunos, deixando lacunas nas informações e dados sobre taxas gerais de vitimização e tipos de agressões sofridas por professores, bem como sobre os perpetradores destas violências. Estudos mais recentes têm buscado suprir essa lacuna, destinando atenção à violência sofrida por professores (SOARES; MACHADO, 2014; MELANDA et al., 2018; PEREIRA; ZUIN, 2019; ARAGÃO PINHEIRO et al., 2020; PLASSA; PASCHOALINO; BERNARDELLI, 2021).

Uma pesquisa internacional sobre ensino e aprendizagem denominada Teaching and Learning International (TALIS) publicada em 2014, conforme dados do Instituto Nacional de Estudos e Pesquisas Educacionais (INEP), entrevistou mais de 100 mil professores do segundo ciclo do ensino fundamental e médio, em 34 países. No Brasil, participaram da pesquisa 14.291 professores do ensino fundamental $\left(6^{\circ}\right.$ ao $9^{\circ}$ ano) e seus respectivos diretores das 27 unidades federativas. A amostra incluiu professores das redes federal, estaduais, municipais e, também, escolas privadas. O questionário foi respondido em 2012. De acordo com os resultados da TALIS, $12,4 \%$ destes professores sofre intimidação ou ofensa verbal praticadas por alunos semanalmente, e o Brasil está em primeiro lugar no ranking de violência escolar em geral (INEP, 2014). ${ }^{1}$

Machado e Carvalho (2013) apontam que as violências no ambiente escolar acarretam um estado de insegurança e medo em todo o contexto da instituição, para todos os atores sociais implicados nesse processo, incluindo-se a equipe pedagógica, professores, funcionários, pais e alunos.

É importante destacar que a ligação entre o contexto escolar e a violência se circunscreve numa estrutura complexa de relações sociais que se expressam na escola e adquirem características próprias naquele ambiente. Assim,

[...] a violência nas escolas possui identidade própria e, ainda que seja no plano simbólico, se infiltra nas relações entre professores, alunos e demais funcionários da escola. Nesse contexto, a função educativa encontra-se submetida a tensões. Entretanto, sobre ela, repousam todas as esperanças de melhoria da sociedade futura (ABRAMOVAY; RUA, 2002, p.53).

\footnotetext{
1 A violência não foi apresentada conceitualmente no relatório nacional da pesquisa, mas, foi incluída como um
} indicador que compõe a análise da gestão escolar. 
À medida que se espera da escola a contribuição para a formação cidadã, legitimamente em perspectiva humanista para um projeto de sociedade justa e igualitária, a violência neste espaço é um problema que demanda atenção e provoca tensionamento sobre a função social da escola.

Vieira et al. (2009) sinalizaram que, no que se refere às violências praticadas por alunos no contexto atual, a escola se modifica diante das atitudes dos discentes, à medida que precisa lidar com situações que comprimem a proposta pedagógica. É importante ressaltar que o comportamento violento dos atores sociais na escola também demonstra as fragilidades da própria formação atitudinal (aquela relativa a valores e condutas éticas), da qual a escola deve participar complementando o papel da instituição familiar.

Professores brasileiros são vítimas constantes da violência no espaço escolar. Segundo Plassa, Paschoalino e Bernardelli (2021), estas violências afetam a qualidade do ensino e, consequentemente, traz prejuízos ao aprendizado e formação dos alunos como cidadãos. Os autores indicaram em seus estudos que "características pessoais dos professores como ser homem, mais velhos e receber baixo salário aumentam a probabilidade de relatos de violência contra a vida" (PLASSA; PASCHOALINO; BERNARDELLI, 2021, p. 247), ou seja, expressão de violência que pode ser fatal.

Embora a produção de estudos acadêmicos sobre a violência contra professores de modo geral tenha aumentado (MELANDA et al., 2018), especialmente na última década, quando se busca trabalhos sobre áreas específicas do conhecimento, como a de professores de Educação Física, os trabalhos são escassos. Em levantamento feito para este trabalho, a única pesquisa a enfatizar a violência sofrida por professores de Educação Física foi a de Levandoski, Ogg e Cardoso (2011). Em sua pesquisa, estes autores investigaram professores de Educação Física do estado do Paraná e constataram que 87,3\%, dos 102 professores participantes (que responderam a um questionário), já vivenciaram algum tipo de violência na escola. Uma grande parte relatou receber insultos semanais de alunos.

Em meio ao cenário apresentado, percebe-se a importância e relevância de investigar a violência contra professores na educação básica em suas diversas realidades. Nesse estudo, em específico, o objetivo geral é identificar e analisar concepções e percepções de violência sofridas por professores de Educação Física. Esta investigação pretende, também, identificar eventuais peculiaridades, especificidades e/ou possíveis diferenças entre a percepção de violência sofrida por professores de Educação Física e professores de outras áreas do conhecimento. Interessa-se, peculiarmente, pelas violências contra professores praticadas por alunos, articulando-se uma discussão sobre a valorização profissional na cidade de Viçosa, Minas Gerais, Brasil. 


\section{METODOLOGIA}

Esta pesquisa é de natureza qualitativa, descritiva e exploratória. Segundo Lakatos e Marconi (2010), essa caracterização corresponde a pesquisas que têm por objetivo analisar e interpretar fatos dinâmicos de uma da realidade social particular aos quais o tratamento analítico não se pretende numérico ou estatístico na busca pela compreensão do fenômeno. Para Vieira e Zouain (2005), a pesquisa qualitativa é de suma relevância para depoimentos, discursos e significados, considerando a descrição dos fatos e dos elementos que os cercam.

A coleta de dados foi conduzida a partir da realização de entrevistas semiestruturadas com professores de Educação Física e de outras áreas do conhecimento, atuantes na educação básica pública do município de Viçosa, Minas Gerais, Brasil. Através da entrevista o pesquisador busca obter informes contidos na fala dos atores sociais, para assim explorá-los direcionando o foco para o objeto de sua investigação (MINAYO, 2001). Na entrevista semiestruturada, a produção do roteiro de entrevistas, bem como a condução das mesmas, permite ao investigador o aprofundamento de uma relação intersubjetiva na interação com o entrevistado, conforme aponta Minayo (2001).

$\mathrm{O}$ roteiro de entrevistas, portanto, embasa a sequência de abordagem dos temas, mas, permite ao entrevistador uma interlocução para acessar especificidades do contexto cultural, do diaa-dia dos sujeitos, considerando o indivíduo "um exemplar restrito e peculiar de sua cultura" (MINAYO, 2001, p. 266). Cada entrevista foi gravada e posteriormente transcrita.

No caso deste estudo, após o registro de dados como idade, sexo e área de atuação, o roteiro contemplou as seguintes: Qual a sua concepção de violência? Quais os tipos de violência que você conhece? Na sua atuação profissional, você já sofreu violências praticadas por alunos dentro ou fora de sala de aula? Se sim, como foi a violência sofrida? Como você reage quando sofre violência? Se você não sofreu violência pessoalmente, conhece casos de violência contra professores na sua escola? Como essa violência ocorreu? No exercício da sua profissão, você já teve medo de dar aula devido à violência? A escola aborda/tematiza a violência com os alunos em projetos ou outras ações? Em suas aulas, você tematiza a violência? Com que frequência há casos de violência contra professores em suas aulas ou na escola de maneira geral? Como você intervém sobre eles? Você conhece algum tipo de apoio ou dispositivo legal para o professor caso ele sofra violências? Considerando a violência contra professores, quais sensações/sentimentos te ocorrem como professor de escola pública nos dias atuais? 
As questões descritas acima foram norteadoras e, a partir das respostas dos sujeitos, foram construídas interações para contemplar detalhamentos de algumas das respostas. A escolha dos sujeitos participantes foi intencional, pois, é a rede pública da educação que representa de maneira mais expansiva o acesso à educação como um direito e acolhe atores sociais de diversas realidades sociais. Ademais, optou-se por realizar as entrevistas com professores do ensino médio, etapa final da educação básica, pois, pressupõe-se que neste nível de ensino o professor lida com estudantes que refletem atitudes e valores de seus anos de escolarização e diferentes instâncias socializadoras.

Assim, foram enviados convites de participação no estudo para as sete escolas públicas de Viçosa, MG que ofertam o ensino médio, por meio de equipes pedagógicas e/ou equipes gestoras, pessoalmente e/ou por contato eletrônico, apresentando os objetivos do estudo e garantias relacionadas aos procedimentos éticos da pesquisa. $\mathrm{O}$ convite se dirigia a professores de Educação Física e professores de outras áreas do conhecimento. Os professores que aceitaram participar assinaram ao Termo de Consentimento Livre e Esclarecido (TCLE). ${ }^{2}$

A partir das transcrições das entrevistas, utilizou-se a técnica de análise de conteúdo, que consiste em três fases principais, conforme estabelece Bardin (2011). A primeira fase é a préanálise, que consiste em sistematizar as ideias, selecionando-se os elementos principais contidos no conteúdo das mensagens que, no caso deste estudo, foi operacionalizada a partir das transcrições das entrevistas. Assim, destacaram-se nesta fase indicadores para a interpretação de informações sobre concepções, percepções e experiências de violências sofridas por professores. A segunda fase da análise de conteúdo é a exploração do material. Esse processo não segue uma linearidade do conteúdo, mas, agrupa recorrências temáticas que, no caso deste estudo, estavam explicitadas nas falas dos entrevistados. Identificados estes agrupamentos, compõem-se unidades de contexto (categorias) que relacionam as ideias apresentadas pelos interlocutores. Na última fase, então, operam-se interpretações e inferências como resultados, que são ponderados por meio da mediação com a literatura científica (BARDIN, 2011), mobilizando perspectivas teóricas para estabelecer uma discussão dos dados e com os dados.

\section{RESULTADOS E DISCUSSÕES}

Responderam ao convite dentro do prazo do cronograma da pesquisa um total de dez professores, que assinaram o termo e foram entrevistados. Cinco professores participantes são da

\footnotetext{
${ }^{2}$ Embora, a título de informação sobre o contexto, tenhamos buscado dados sobre o número total de professores que atuam no ensino médio na cidade por área de conhecimento, não obtivemos retorno sobre estes dados junto aos órgãos públicos consultados.
} 
área de Educação Física e cinco professores são de outras áreas do conhecimento, a saber: Ciências, Artes, Língua Portuguesa e Física. Dentre os entrevistados, havia participantes de quatro escolas diferentes, sendo três localizadas na região periférica e uma na região central da cidade de Viçosa, Minas Gerais. As entrevistas foram realizadas presencialmente entre dezembro de 2019 e 12 fevereiro de 2020, com cada professor, nas escolas em que trabalhavam. Os entrevistados tinham entre 25 e 48 anos de idade.

Por meio da pré-análise e exploração do material, foram estabelecidas três categorias: 1) escola como espaço de reprodução de violências; 2) professores e o cotidiano de violências; 3) violências e desvalorização profissional. Assim, os trechos das entrevistas citados nas categorias de análises serão denominados por códigos compostos de letras e números. Os professores de Educação Física são classificados pela sigla PEFI e os professores de outras áreas POA. Interpretações e inferências dos resultados estão apresentadas a partir das categorias criadas, conforme sistematização abaixo.

\section{Escola como espaço de reprodução de violências}

A violência nas escolas é multifatorial e abrange não somente a violência contra professores propriamente dita, mas, também a violência entre os próprios estudantes. A presença da violência no ambiente escolar foi percebida como algo cotidiano, indistintamente, entre professores de Educação Física e de outras áreas, como se ilustra na fala abaixo:

POA 3: Já, de aluno com aluno principalmente menino contra menina, chamar de fedorenta, macaca, coisas assim, palavras de baixo escalão mesmo, assim, bem palavras chulas. E você tem que fazer todo um trabalho mediador de tentar acalmar os ânimos, porque é bem triste isso, é bem complicado. Já vi uma professora tendo problemas com uma aluna e chamar a mãe e a mãe tentar bater nessa professora na porta da escola. A mãe ficou bem agressiva com a professora... Ameaçou bater, ficou jogando pedra na janela da casa dessa professora.

PEFI 4: Muita violência, muita violência na escola [...] Hoje de manhã nós chegamos, acho que isso foi ontem ou antes de ontem, hoje de manhã nós chegamos aqui na escola e sabe o que que tinha? Você vai achar assim, horrível: cocô humano! Fezes humanas esfregadas na mesa inteira da cantina, nas maçanetas da porta da cantina, no cadeado, no orifício aonde coloca a chave. Aí foi chamado a polícia, foi feito um boletim de ocorrência e aí ocorreu isso. A gente chegou na escola hoje e ver essa cena lamentável...Então, assim, é violência! Explícita, grave, absurda, né?!

POA 2: Já, de aluno com aluno, professor, aluno que empurra o outro, discussões, palavrões, que também é uma forma de violência, professor que chama atenção e aluno não respeita. 
Verificou-se, a partir das entrevistas, que parte dos professores entrevistados tematiza a violência com os alunos em suas aulas ou projetos, com intuito de diminuir episódios nesse sentido. Alguns, relataram obter resultados positivos, como se nota a seguir:

PEFI 4: O aluno não sabe o que é violência. Então xingar o colega, ele acha que é normal, mas, não é! É uma agressão verbal e, talvez, para ele no ambiente que ele vive se tornou normal...Então, isso é importante de ser trabalhado, a partir do momento que você sabe, que o que você está fazendo não é normal, você se preocupa mais. Se ninguém te alerta sobre isso, né?! Então, é muito importante, faz a diferença.

PEFI 3: Eu sou professora de Educação Física, então a gente sempre vê casos de violência, é... No esporte, né? De torcidas, agressão entre as torcidas e até morte, né? Costuma ter até morte, é... tem violência entre os jogadores, às vezes até jogo de seleção de Copa do Mundo a gente vê um jogador tratando o outro com violência. E o que que a gente faz? A gente traz para a sala de aula, né? Discute com os alunos essa questão de violência. [...] Então é na escola que a gente tem que estar trabalhando, repudiando qualquer tipo de violência.

Demonstra-se nestas falas que os professores identificam, dentro de sua área de conhecimento, possibilidades para a tematização e o trato pedagógico da violência, investindo suas práticas neste sentido. Não se pretendeu analisar, neste estudo, a organização sistemática dessas ações, se elas ocorrem isoladamente ou de forma consistente ao longo dos planos de ensino, mas, constata-se a presença de iniciativas no trato do tema.

Epistemologicamente, tanto em teorias educacionais mais amplas, quanto na apropriação da Educação Física desses conhecimentos, ressalta-se a perspectiva da escola como mediadora de um conjunto de saberes relacionados à formação sociopolítica, ou seja, formação para a cidadania, para além da qualificação para o mercado de trabalho (SAVIANI, 2009; DARIDO; JUNIOR, 2010). Essa compreensão sinaliza para a responsabilidade de discutir sobre temas sensíveis à realidade conjuntural na escola, buscando diretamente impactar o cotidiano do aluno, inclusive quanto às diversas expressões da violência.

O professor é, de fato, um profissional fundamental para mediar a visão de mundo e de cidadão, orientados para um projeto de sociedade pacífica (SAVIANI, 2009). Porém, é preocupante notar que professores são alvos constantes de violência, em que um dos principais agentes é o próprio aluno, como se apresenta na discussão da categoria a seguir. 


\section{Professores e o cotidiano de violências}

Constatou-se que a violência contra professores é parte da rotina diária dos entrevistados. A maioria dos professores, ao apresentarem suas concepções sobre violência, compreende o termo reportando-se às diferentes formas em que ela se expressa, como se pode verificar a seguir:

PEFI 1: Então, existe vários tipos de violência, tem a violência física e a violência verbal né, que eu entendo sobre elas e, dessas duas formas você pode está é... cometendo uma violência contra uma pessoa.

POA1: Bom, existe a violência física, moral e verbal.

Mesmo que grande parte dos professores não tenham apresentado definições ou conceitos abrangentes sobre violência quanto à violação de direitos, por exemplo, todos relataram que sofrem violência no meio escolar. A violência contra professores é retratada como uma situação cotidiana, onde docentes são cercados por violências que afetam diretamente o exercício profissional e a saúde, como se reforça nos relatos abaixo:

POA 5: Eu vejo assim, uma violência muito escondida frente a minha pessoa. [...] Assim, não deboche frontal com a palavra, mas, eu sinto no rosto deles que, às vezes, a gente não significa nada para eles ali, como se a gente não existisse. Além das ameaças, tem um aluno que me perseguiu da escola até na (sic) minha casa. Então, assim, eu tive que pedir o (sic) meu irmão para me buscar de carro, pois, eu sempre ando a pé e aí eu fiquei com medo, sabe? Isso me trouxe uma série de problemas psicológicos, entendeu? Falha de memória, eu dormia e acordava assustado.

Se, por um lado, detecta-se na literatura que a escola exerce violência simbólica como instituição quando seus agentes tratam estudantes com desprezo, expressões faciais de deboche e intimidações (COSTA, 2011), por outro, a dinâmica entre os atores sociais da escola também implica a vitimização dos professores deste mesmo tipo de violência como se constatou na fala acima. Ou seja, perpetua-se uma cultura de violência no ambiente escolar que, no caso da violência simbólica, pressupõe uma naturalização e, tomando por perspectiva o professor vitimado, culmina no processo de desvalorização profissional da figura do professor, como se abordará de modo específico na última categoria.

É importante situar a complexidade das implicações dessa cultura em que condições precárias relacionadas ao trabalho diário dos professores, em específico as violências, ampliam diretamente os índices de adoecimento psíquico desta classe de trabalhadores (FERREIRA, 2011). A consequência é uma alta demanda de afastamentos do trabalho por doenças psicológicas, 
impedindo ao professor de realizar a sua profissão e, em alguns casos, o abandono da profissão conforme pontuam Santini e Neto (2015).

Durante as entrevistas, muitos professores emocionaram-se em seus relatos, demonstrando as suas aflições neste cotidiano. Dentre os entrevistados, há um relato que revela certa peculiaridade aos professores de Educação Física:

PEFI 4: É obvio que o professor de Educação Física não sofre violência, ele não dá aula. Por que que eu falo que ele não dá aula? Porque ele não se indispõe com o aluno. Ele leva os alunos para a quadra e deixa o aluno jogar bola. Que aluno que vai achar ruim um professor assim? O professor de Educação Física, na maioria das vezes, ele se torna amiguinho do aluno: "Ah, vem cá, vamos jogar uma bola aqui". "Ah, vocês querem fazer o que hoje?"

A fala de PEFI 4 demonstra um conhecido problema na prática pedagógica do professor de Educação Física, que muitas vezes é destituída de intencionalidade pedagógica, e sequer pode ser caracterizada como "aulas" em certas situações. Isto relembra debates sobre a necessidade de superar a banalização da prática pedagógica em Educação Física, reconhecendo-se a complexidade docência e inovação pedagógica (FARIA; BRACHT; MACHADO, 2010). O relato segue:

PEFI 4: A Educação física é uma área do conhecimento. Essa área de conhecimento tem que ser passada para os alunos e os professores de Educação física terão os mesmos problemas que os outros professores, e até mais, porque nós não temos as notas para coibir a violência. Hoje um professor de biologia, história, matemática, tem nota. "Ah, você xingou? Menos um ponto." Então o aluno fica preocupado, porque ele quer passar de ano e o professor de Educação Física não tem isso. Aquele que realmente dá aula, que eu falo que é o meu caso, porque eu me esforço, (...) e quando eu me esforço eu sofro violência, quando eu dou aula, eu sofro violência. Porque o aluno ele não quer aula, ele quer o "rola bola" que ele foi acostumado há tantos anos na escola.

A Educação Física escolar é representada como uma área desvalorizada frente as outras áreas do conhecimento na fala de PEFI4, fato reforçado por uma cultura escolar sem intencionalidade pedagógica que desconsidera os conteúdos e avanços didático-metodológicos da área (DARIDO; JUNIOR, 2010). Esse sistema, é decorrente de um longo processo de desinvestimento pedagógico, oriundo de uma engrenagem histórica complexa e muito debatida na área, como a cultura do "rola bola" (DESSBESELL, 2014).

Esse processo também aparece no relato de PEFI5, mas, por outra perspectiva. Para ele, a conduta de esquivar-se do trabalho docente na aula de Educação Física torna o ambiente menos propicio à violência, pois, o aluno faz com a aula o que ele quiser e o professor não intervém: “O aluno, ele vai fazer o que ele quer. E se o professor se impor, eles recusam a fazerem a aula. Temos que saber dosar" (PEFI 5). No relato do entrevistado nota-se que o fato do professor exercer o seu 
papel afeta diretamente os casos de violência contra eles. É uma tensão peculiar à área da Educação Física nos dados deste estudo.

Outra questão pontuada por PEFI 4 foi a nota. É fato que o exercício da docência é tensionado por problemas sociais que incidem sobre a atividade profissional. Os instrumentos avaliativos, mais especificamente a falta de atribuição de notas, foi mencionado como fator que agrava o problema da violência contra professores de Educação Física. A disciplina Educação Física não atribui nota somativa nas escolas públicas em que atuam os professores entrevistados. Cita-se, entretanto, a nota como estratégia de punição, o que destoa de teorias educacionais contemporâneas sobre a avaliação do processo de ensino-aprendizagem, inclusive aquelas apropriadas pela epistemologia da Educação Física (DARIDO; JUNIOR, 2010). Parece urgente e necessário que os avanços epistemológicos das teorias da educação e da própria Educação Física se materializem no planejamento, no trato pedagógico do conteúdo e intervenções para a formação cidadã, para desvincular a ideia de que a Educação Física é a área do fazer meramente recreativo e sem intencionalidade, ou que a avaliação seja mecanismo de punição (TAVARES; FONSECA, 2014).

Quanto aos tipos de violência relatados nas entrevistas, não houve diferenças por área do conhecimento, pois, todos os professores pesquisados disseram que já sofreram violência, seja ela física, ameaça, verbal, dentre outras, como se ilustra a seguir:

PEFI 4: Já sofri violência verbal, já sofri tentativa de violência física, porque um aluno arremessou um chinelo em mim...e verbal então, muita! Muita violência verbal de enfrentamento, muito enfrentamento... Ah! Só que eu esqueci de falar, meu pneu da moto também foi esvaziado, só pra (sic) constar.

POA 3: Já, eu já sofri ...no primeiro dia de aula ele (um aluno) disse que a última professora de português dele, ele quebrou o braço. Foi em tom de ameaça.

Em geral, todos os entrevistados reportaram-se a episódios de diferentes tipos de violência. Por estarem cercados pela violência, peculiarmente aquela que o aluno é o agente desse ato, os professores reconhecem implicações psicológicas e desmotivação profissional, como se verifica nos relatos abaixo:

POA 5: Medo de dar aula eu sempre tive [...] a todo momento eu tenho. Eu acho que nós não temos $100 \%$ de segurança nas escolas não, entendeu? ...Então, isso atrapalha a condução da aula, isso leva ao estresse, ao extremo estresse do professor, dentro da profissão. [...] e não somente eu, eu vejo dentro da profissão que os colegas entram na sala sempre com um pouco de insegurança, a gente não sabe a reação do aluno. 
PEFI 3: Medo, mas, um medo assim... porque o aluno sob o uso de drogas, né?! Ele, às vezes, se torna violento. Às vezes nem é consciente, né? Se torna mais corajoso e... já teve um caso de um aluno que já entrou armado e queria matar a diretora. A gente estava lá dentro da escola, ele chegou armado e falou: "- Cadê a diretora? Eu vou matar ela!" Ela teve que se esconder ${ }^{3}$.

Os relatos desse cotidiano de violências, assemelha-se com os resultados de De Paula, Kodato e Dias (2013, p.248) em que os incidentes na relação professor-aluno são colocados como inevitáveis por parte dos professores, o que os autores interpretaram com "representação fatalista de violência na escola".

As implicações são ainda mais amplas quando se considera, por exemplo, de acordo com Santini e Neto (2015), que violências sofridas por professores afetam seu emocional. O professor sente medo, ansiedade e muitas vezes depressão. De fato, algumas das causas que circundam a violência de alunos contra professores são os problemas sociais correlatos como, por exemplo, o uso drogas e uso de armas dentro da escola. É preciso lembrar que estes são problemas estruturais da sociedade. Esses fatos dificultam o trabalho do professor na condução das aulas, fazendo com que o desrespeito circunde todo esse ambiente, como aborda a próxima categoria de análise relativa à desvalorização do professor da rede pública de ensino.

\section{Violências e desvalorização profissional}

Professores, de modo geral, tem sido alvo de violências e agressões acarretando, de maneira direta ou indireta, impactos em sua motivação profissional (MATOS; VIANA GURGEL, 2012). A desvalorização do professor nos dias atuais é reforçada a cada dia por toda a sociedade e pelo Estado, caracterizando-se, inclusive, como uma violência simbólica, como se percebe nos relatos dos seguintes professores:

POA 3: Desmotivado, desvalorizado, infelizmente não tem muito saldos (sic) positivos nessa faixa emocional do professor, não. O que que acontece? Muitos persistem por amor à profissão, que eu acho que tem que ser feita com amor mesmo! Conheço professores que tomam rivotril e uma professora que eu admiro muito, que foi um espelho para mim, aposentou um pouco antes, perdeu uma porcentagem do salário ... Eu não quero chegar no rivotril, porque ela estava se sentindo agredida no sentido de não conseguir dar as suas aulas.

PEFI 3: O professor da rede estadual ele é muito desvalorizado, em todos os aspectos, no financeiro principalmente. No nosso salário ... a gente não é valorizado, né? A gente briga por uma coisa e não consegue... o piso salarial

\footnotetext{
${ }^{3} \mathrm{Na}$ interlocução com o entrevistado, foi possível confirmar tratar-se de arma de fogo.
} 
nacional era para ter... ser pago agora, ser atualizado. Já tem dois anos que a gente não tem reajuste nem nada.

POA 4: Desvalorizada e desmotivada, tanto financeiramente, pedagogicamente falando, profissionalmente, porque tem que dar aula em duas escolas para poder conseguir um salário melhorzinho, então fica sobrecarregado. A parte pedagógica, tem escolas que tentam ajudar, mas, não conseguem devido a esse tipo de outros problemas (sic), quando não é com pai, é de aluno com aluno, conflitos que tem na escola mesmo.

Todo esse processo parece constituir um ciclo /ou uma cultura de desvalorização. O professor desvalorizado socialmente, vulnerável, é vítima potencial de diversas violências que banalizam o seu papel social. Por sua vez, a recorrência da própria violência desvaloriza ainda mais a prática docente, como se percebe nas falas a seguir:

POA 5: O professor não tem voz ativa, entendeu? Isso dificulta muito e desestimula a profissão e favorece a violência... E essa violência vem mesmo da família ou da própria sociedade que dá cobertura para favorecer essas situações e cada vez mais essa banalização, tanto do profissional, quanto da educação. Eu vejo dessa forma.

PEFI 5: ...os alunos percebem, né? Que o ambiente é desvalorizado e os professores estão desmotivados, então eles percebem que o professor está desmotivado, não está nem aí mais.

A ação pedagógica situa-se dentro de uma estrutura que reproduz violências (inclusive a simbólica) trazendo implicações para a vida pessoal e profissional do professor (COSTA, 2011). Os entrevistados referem-se à desmotivação e desvalorização que são processos que, conforme apontam Gurgel, Viana e Matos (2012) comumente levam professores abandonarem a profissão. No estudo de Pereira e Zuin (2019), professores de Rio Branco, Acre, associaram a violência que sofrem ao enfraquecimento de sua autoridade, relatando que percebem que seu desempenho profissional é afetado por isso. No estudo, os autores dizem que "ficou evidente que estes (os professores $)^{4}$ não são vítimas diretas de graves violações, mas de microviolências, entretanto, guiados por um imaginário da violência escolar, agem como se assim o fossem" (PEREIRA; ZUIN, 2019, p.1).

É importante considerar que, além de toda a desvalorização comum à percepção dos docentes, os professores de Educação Física entrevistados destacaram a peculiaridade do espaço de sua prática pedagógica como um ambiente mais propenso a expressões de violência de forma geral. De fato, a Educação Física tem a peculiaridade de utilizar espaços abertos como pátios e quadras poliesportivas para atividades dos seus conteúdos. Sobre isso os entrevistados ressaltam que:

\footnotetext{
${ }^{4}$ Adendo da autoria.
} 
PEFI 3: Há o fato de que eu vou ter que pegar a bola para terminar a aula, para entrar um outro grupo, e aí tem um ou outro aluno que não quer fazer, quer atrapalhar. O próprio aluno, por gostar da pessoa, do profissional, ele fala assim: “Oh, não faz isso com o professor, não!” Aí ele vai lá e pega a bola e me entrega.

PEFI 4: Quando você está sentado dentro de uma sala de aula, na sua mesa, na sua cadeira, é mais difícil você se levantar e ir até o colega...Como é uma sala pequena, o professor vai ouvir o aluno xingar e tudo mais. E então, na quadra, como é um ambiente amplo e não fica tão aos olhos do professor, porque às vezes o menino está lá na frente da quadra e o professor está aqui atrás perto do portão, então às vezes ele não consegue observar a violência, né? Então, por isso que as aulas de Educação Física proporcionam um ambiente mais favorável à violência. Não por causa das práticas corporais, mas, por causa do ambiente mesmo.

Todos os professores pesquisados desconhecem qualquer tipo de apoio específico a ele, caso sofra algum tipo de violência no exercício de sua profissão, conforme se destaca abaixo:

PEFI 1: Eu te confesso que eu desconheço.

PEFI 2: Hum... programa assim não. Creio que não. Eu desconheço, talvez tenha, mas eu não sei não.

POA 3: Infelizmente não. Eu até quero. Foi até bom você ter perguntado que eu vou procurar a saber mais disso, mas, não, não mesmo. Eu acho, que as escolas deveriam ter psicólogos para os professores e para os alunos.

O Estado de Minas Gerais, no ano de 2017, propôs uma lei que ampara a violência contra professores. Trata-se da Lei 22. 623, que estabelece medidas e procedimentos de casos de violência contra professores ocorridos no meio escolar, seja ela direta ou indireta, que ocasiona em um dano patrimonial, psiquiátrico ou psicológico, ameaça a sua integridade física ou patrimonial, lesão corporal e ações que causam a morte (LEGISLAÇÃO MINEIRA, 2017). Essa lei, estabelece providências específicas a serem tomadas, de três a trinta e seis horas após a agressão, sendo a primeira iniciativa, acionar a polícia militar e realizar um boletim de ocorrência. A posteriori, o servidor poderá mudar de turno ou de local de trabalho ou se afastar de suas atividades. A Lei 22.623 do estado de Minas Gerais é desconhecida por todos os entrevistados. Os professores deixaram evidente que não sabem ao certo qual ação ou medida tomar ao sofrer qualquer tipo de violência. Isso tende a perpetuar e acumular problemas psicológicos, desmotivação e desvalorização. 


\section{CONSIDERAÇÕES FINAIS}

Este estudo identificou e discutiu perspectivas, concepções e relatos sobre a violência sofrida por professores do ensino médio da rede pública de ensino da cidade de Viçosa, MG. A pesquisa constata, como outras, evidências de que a violência é um problema social que adentra escolas da cidade de Viçosa cotidianamente. A escola fica tensionada entre seu papel social voltado para a formação cidadã, inclusive para uma formação ética e atitudinal e as compressões de uma sociedade violenta.

A violência contra professores é marcada no cotidiano de cada um, se expressando de diversas formas, como ameaças e agressões verbais, físicas e simbólicas, constituindo um cenário de medo. Essas manifestações se apresentam para professores de Educação Física e de outras áreas do conhecimento em pontos comuns e outros peculiares.

São pontos comuns: as violências afetam professores em seu cotidiano, causando medo e insegurança; o desconhecimento de mecanismos legais ou de outra natureza de apoio ao professor caso ele sofra violência na escola; o sentimento de desvalorização.

Dessa forma, é preciso aprimorar os mecanismos para proteger o professor e coibir a violência em todo o ambiente escolar, contemplando medidas educativas considerando o todo social. Indispensavelmente, é preciso tratar a violência como um aspecto interdisciplinar e que merece atenção continuamente em toda a escola, sendo de responsabilidade não apenas dos professores, mas, de toda a comunidade escolar e extraescolar, a partir de ações sistemáticas, amparadas por políticas institucionais e políticas educacionais que rompam com o ciclo de desvalorização.

Ao analisar a Educação Física, algumas peculiaridades foram encontradas, sendo que elas tangenciam a questão da intencionalidade pedagógica. Os relatos dos docentes demonstraram que persistem dificuldades de que os alunos compreendam a área como um componente curricular que contribui para a formação humana e cidadã de maneira ampla. Essa dificuldade perpassa toda a cultura escolar e se escancara ao analisar o problema da violência escolar.

Outra especificidade reporta-se ao espaço físico das aulas que, em diferentes perspectivas, agrava a violência contra o professor de Educação Física e entre alunos, segundo relatos, pela dificuldade de gerenciar o espaço e o número de alunos por turma nas aulas.

A singularidade da Educação Física no que diz respeito à falta da nota em avaliação somativa foi mencionada como mecanismo de coibir a violência. Na fala de docentes, a ausência de notas parece colaborar como um ingrediente a mais de desvalorização do professor de Educação 
Física, o que potencializaria a vulnerabilidade dele à violência. Neste estudo, acredita-se que essa questão deve ser mais discutida no sentido de que a avaliação em Educação Física deve ser vista como parte do processo de ensino e aprendizagem da área, com sua intencionalidade em sua contribuição para a formação humana. Os paradigmas da avaliação na fala dos docentes e nos sistemas de ensino parecem precisar superar a avaliação como instrumento de punição. Alguns professores vêem a avaliação como um fator que descredibiliza a compreensão da área.

A partir das falas dos entrevistados, sugere-se a presença de uma equipe pluridiscipinar nas escolas, com o intermédio de psicólogos e assistentes sociais envolvidos no sistema educacional, para que amparem toda a classe pedagógica e, também, para os próprios alunos, colaborando para que estes possam compreender-se em processo de formação cidadã.

Este estudo ressalta a necessidade de um maior investimento em pesquisas qualitativas sobre a violência contra professores. Também são necessários mais estudos sobre a violência contra professores de Educação Física, que se encontram escassos na literatura. Com isso, acredita-se que a presente contribuição possa somar para o entendimento das especificidades da Educação Física no que se refere à violência contra professores. Dados sobre mais realidades, articulados com as demandas inerentes à prática pedagógica na área são necessários para orientar ações institucionais, reivindicações da classe e políticas educacionais para transformar essa realidade.

\section{REFERÊNCIAS}

ABRAMOVAY, Miriam. Enfrentando a violência nas escolas: um informe do Brasil. In: UNESCO. Violência na escola: América Latina e Caribe. Brasília: UNESCO, 2003. p. 85-150.

ABRAMOVAY, Miriam. Cotidiano das escolas: entre violências. Brasília: UNESCO, Observatório de Violência, Ministério da Educação, 2005.

ABRAMOVAY, Miriam; RUA, Maria das Graças. Violências nas escolas. 2. ed. Brasília: UNESCO, 2002.

BARDIN, Laurence. Análise de conteúdo. São Paulo: Edições 70, p. 229, 2011.

BONVICINI, Constance Rezende; SILVA, Jean Carlos da. Violência e promoção da saúde. Revista

Psicologia e Saúde em Debate, v. 1, n.1, p. 78-88, 2015. Disponível em:

http://psicodebate.dpgpsifpm.com.br/index.php/periodico/article/view/8. Acesso em 15 jun. 2019.

CARDIA, Nancy das Graças; SCHIFFER, Sueli Terezinha Ramos. Violência e desigualdade social. Ciência e Cultura, São Paulo, v. 54, n. 1, p. 25-31, 2002. Disponível em:

http://cienciaecultura.bvs.br/scielo.php?script=sci_arttext\&pid=S0009-67252002000100018. Acesso em 24 abr. 2019.

COSTA, Polyana Andreza da Silva. Violência no cotidiano escolar: a visão de professores que atuam no ensino fundamental de escolas públicas do município de Corumbá - MS. 2011. 248f. Dissertação (Mestrado em Educação) - Universidade Federal do Mato Grosso do Sul, Corumbá, 2011. Disponível em: 
https://ppgecpan.ufms.br/files/2013/08/POLYANAANDREZADASILVACOSTA.pdf. Acesso em: 19 abr. 2019.

DARIDO, Suraya Cristina; JUNIOR, Osmar Moreira de Souza. Para ensinar Educação Física:

Possibilidades de intervenção na escola. 6.ed. Campinas, SP: Editora Papirus, 2010.

DESSBESELL, Giliane. Não sou desse tipo! Professores de educação física e o temor de serem confundido com um "rola bola". Revista Didática Sistemática, v.16, n.1, p. 100-112, 2014. Disponível em: https://periodicos.furg.br/redsis/article/download/5122/3167. Acesso em 23 jan. 2020.

DE PAULA, Alexandre da Silva; KODATO, Sérgio; DIAS, Francielle Xavier. Representações sociais da violência em professores da escola pública. Estudos Interdisciplinares em Psicologia, v. 4, n. 2, p. 240257, 2013. Disponível em: http://pepsic.bvsalud.org/scielo.php?script=sci arttext\&pid=S223664072013000200008. Acesso em: 20 mai. 2019.

ELIAS, Norbert; DUNNING, Eric. A Busca da Excitação. Lisboa, Difel, 1992.

FARIA, Bruno; BRACHT, Valter; MACHADO, Thiago. Inovação pedagógica na Educação Física: o que aprender com práticas bem-sucedidas? La Educación Física y el Deporte, v. 1, p. 11- 28, 2010. Disponível em: https://dialnet.unirioja.es/servlet/articulo?codigo=3217498. Acesso em: 10. jan. 2020.

FERREIRA, Cristiane. Adoecimento psíquico de professores: Um estudo de casos em escolas estaduais de educação básica numa cidade mineira. 2011. 79f. Dissertação (Mestrado em Administração) - Faculdade Integrada de Pedro Leopoldo, Pedro Leopoldo, 2011. Disponível em:

https://www.fpl.edu.br/2018/media/pdfs/mestrado/dissertacoes_2011/dissertacao_cristiane_ferreira_magalha es_2011.pdf. Acesso em 20 abr. 2019.

MATOS, Francisco Alex da Silva; VIANA, Samanda Silvéria Alves; GURGEL, Carmesina Ribeiro A violência contra professores: saberes e práticas. Campina Grande: Realize Editora, 2012.

INSTITUTO NACIONAL DE ESTUDOS E PESQUISAS EDUCACIONAIS. Pesquisa Internacional sobre Ensino e Aprendizagem. Relatório Nacional (TALIS). Brasília: INEP, 2014, 33p. Disponível em: https://download.inep.gov.br/acoes internacionais/pesquisa talis/2013/talis2013 relatorio brasil.pdf. Acesso em: 29 jun. 2019.

LAKATOS, Eva Maria; MARCONI, Marina de Andrade. Técnicas de pesquisa: planejamento e execução de pesquisas, amostragens e técnicas de pesquisas, elaboração, análise e interpretação de dados. São Paulo: Atlas, 1996.

LEVANDOSKI, Gustavo; OGG, Fabiano; CARDOSO, Fernando Luiz. Violência contra professores de Educação física no ensino público do estado do Paraná. Motriz, Rio Claro, v.17, n.3, p. 374-383, 2011. Disponível em: https://www.scielo.br/j/motriz/a/n5LmsSrSCD5Pfv9nwwQP5TM/?lang=pt\&format=pdf. Acesso em: 10 out. 2019.

LEGISLAÇÃO MINEIRA. Lei 22623, de 27 de Julho de 2017. Estabelece medidas e procedimentos para os casos de violência contra profissionais da educação ocorridos no âmbito das escolas públicas estaduais. Disponível em: https://leisestaduais.com.br/mg/lei-ordinaria-n-22623-2017-minas-gerais-estabelecemedidas-e-procedimentos-para-os-casos-de-violencia-contra-profissionais-da-educacao-ocorridos-noambito-das-escolas-publicas-estaduais. Acesso em $10 \mathrm{dez} .2019$.

MACHADO, Laêda Bezerra; CARVALHO, Daniele Farias de. Violência escolar, concepções e ações do coordenador pedagógico. Rev. Reflexão e Ação, Santa Cruz do Sul, v. 21, n.1, p. 05-24, 2013. Disponível em: https://online.unisc.br/seer/index.php/reflex/article/view/3195. Acesso em: 21 abr. 2019. 
MELANDA, Francine Nesello; SANTOS, Hellen Geremias dos; SALVAGIONI, Denise Albieri Jodas; MESAS, Arthur Eumann; GONZÁLEZ, Alberto Durán; ANDRADE, Selma Maffei de. Violência física contra professores no espaço escolar: análise por modelos de equações estruturais. Caderno de Saúde Pública, Rio de Janeiro, v. 34, n. 5, p. 1-12, dez. 2018. Disponível em:

https://www.scielo.br/j/csp/a/bt5zJpVCRwwHmXQvbJNVxPq/abstract/?lang=pt\#. Acesso em: 10 dez. 2021.

ORGANIZAÇÃO MUNDIAL DE SAÚDE. Relatório mundial sobre violência e saúde, Genebra, 2002. Tradução: Secretaria de Estado dos Direitos Humanos, Ministério da Justiça, Brasil, 2002.

PEREIRA, Antônio Igo Barreto; ZUIN, Antônio Álvaro Soares. Autoridade enfraquecida, violência contra professores e trabalho pedagógico. Educar em Revista. 2019, v. 35, n. 76, p. 331-351. Disponível em: http://www.scielo.br/j/er/a/H4JvMqH8SdHnBbGyvLhwpvp/abstract/?lang=pt\#ModalArticles. Acesso em: 19 ago. 2021.

PLASSA, Wander; PASCHOALINO, Pietro André Telatin; BERNARDELLI, Luan Vinicius. Violência contra professores nas escolas brasileiras: determinantes e consequências. Nova Economia. 2021, v. 31, n. 01, p. 247-271. Disponível em:

https://www.scielo.br/j/neco/a/vmjWRJDXr4LgshFv77bdTKt/?format=pdf\&lang=pt . Acesso em 8 abr. 2020.

SANTINI, Joarez; NETO, Vicente Molina. A síndrome do esgotamento profissional em professores de Educação Física: um estudo na rede municipal de ensino de Porto Alegre. Revista Brasileira de Educação Física e Esporte. São Paulo, v.19, n.3, p.209-22, jul./set. 2005. Disponível em: https://www.revistas.usp.br/rbefe/article/view/16596. Acesso em: 20 abr. 2019.

SAVIANI, Demerval. Formação de Professores: aspectos históricos e teóricos do problema no contexto brasileiro. Revista Brasileira de Educação, Rio de Janeiro, v. 14, n. 40, p. 142-155, jan./abr. 2009. Disponível em: http://www.scielo.br/pdf/rbedu/v14n40/v14n40a12.pdf. Acesso em: 13 out. 2019.

SCHRAIBER, Lilia Blima; D’OLIVEIRA, Ana Flávia; COUTO, Márcia Thereza. Violência e saúde: estudos científicos recentes. Rev. Saúde Pública, São Paulo, v. 40, p. 112-20, 2006. Disponível em: https://www.scielo.br/j/rsp/a/DNPkpYFGWCHtGRK7G46gk3D/abstract/?lang=pt. Acesso em: 29 abr. 2019.

SOARES, Michele Beltrão; MACHADO, Laêda Bezerra. Violência contra o professor nas representações sociais dos docentes. Respectiva, Florianópolis, v. 32, n. 1, 333-354, jan./abr. 2014. Disponível em: https://periodicos.ufsc.br/index.php/perspectiva/article/view/2175-795X.2014v32n1p333. Acesso em: 05 mai. 2019.

TAVARES, Natacha da Silva; FONSECA, Denise Grosso da. Avaliação nas aulas de Educação Física em escolas de Viamão-RS. Rev. Didática Sistemática, Rio Grande Do Sul, v.16, n.1, p. 113-127, 2014. Disponível em: https://periodicos.furg.br/redsis/article/view/5123. Acesso em 06 abr. 2019.

VIEIRA, Luiza Jane Eyre de Souza; ABREU, Carlos Alberto Pereira de; VALDÊS, Maria Teresa Moreno; OLIVEIRA, Eliany Nazaré de; FERREIRA, Renata Carneiro; CATRIB, Ana Maria Fontenelle. Violência na escola pública: Relatos de professores. Revista Brasileira em Promoção da Saúde, Fortaleza, v.23, n.1, p. 34-42, 2009. Disponível em: https://periodicos.unifor.br/RBPS/article/view/1169. Acesso em 03 out. 2019.

TIRADENTES, Adrielly Rocha. Violência simbólica no contexto escolar: discriminação, inclusão e o direito a educação. Rev. Eletrônica do curso de Direito, Minas Gerais, n.12, p. 33-48, 2015. Disponível em: http://periodicos.pucminas.br/index.php/DireitoSerro/article/view/10903/9551. Acesso em 10 mai. 2019. 


\section{NOTAS DE AUTOR}

\section{AGRADECIMENTOS}

Agradecemos aos professores da rede pública de Viçosa, por participarem deste estudo.

Agradecemos aos membros Laboratório de Estudos e Pesquisas em Educação Física, Escola e Sociedade (LEPEFES), Departamento de Educação Física, Universidade Federal de Viçosa.

CONTRIBUIÇÃO DE AUTORIA - Não se aplica.

FINANCIAMENTO - Não se aplica.

CONSENTIMENTO DE USO DE IMAGEM - Não se aplica.

\section{APROVAÇÃO DE COMITÊ DE ÉTICA EM PESQUISA}

A pesquisa foi aprovada pelo Comitê de Ética e Pesquisas com seres humanos da Universidade Federal de Viçosa no dia 14 de outubro de 2019. Número do Parecer: 3.639 .588

CONFLITO DE INTERESSES - Não há conflito de interesses.

\section{LICENÇA DE USO}

Os autores cedem à Motrivivência - ISSN 2175-8042 os direitos exclusivos de primeira publicação, com o trabalho simultaneamente licenciado sob a Licença Creative Commons Attribution Non-Comercial ShareAlike (CC BY-NC SA) 4.0 International. Esta licença permite que terceiros remixem, adaptem e criem a partir do trabalho publicado, desde que para fins não comerciais, atribuindo o devido crédito de autoria e publicação inicial neste periódico desde que adotem a mesma licença, compartilhar igual. Os autores têm autorização para assumir contratos adicionais separadamente, para distribuição não exclusiva da versão do trabalho publicada neste periódico (ex.: publicar em repositório institucional, em site pessoal, publicar uma tradução, ou como capítulo de livro), com reconhecimento de autoria e publicação inicial neste periódico, desde que para fins não comerciais e compartilhar com a mesma licença.

\section{PUBLISHER}

Universidade Federal de Santa Catarina. Programa de Pós-Graduação em Educação Física. LaboMídia - Laboratório e Observatório da Mídia Esportiva. Publicado no Portal de Periódicos UFSC. As ideias expressadas neste artigo são de responsabilidade de seus autores, não representando, necessariamente, a opinião dos editores ou da universidade.

\section{EDITORES}

Mauricio Roberto da Silva, Giovani De Lorenzi Pires, Rogério Santos Pereira.

\section{EDITOR DE SEÇÃO}

Juliano Silveira

\section{REVISÃO DO MANUSCRITO E METADADOS}

Juliana Rosario; Keli Barreto Santos.

\section{HISTÓRICO}

Recebido em: 30 de agosto de 2021

Aprovado em: 02 de dezembro de 2021 